\title{
Individual and Neighborhood Effects on FHA Mortgage Activity: Evidence from HMDA Data
}

\author{
Zeynep Önder* \\ Faculty of Business Administration, Bilkent University, Bilkent, Ankara 06533, Turkey \\ E-mail: zonder@bilkent.edu.tr
}

Received August 19, 1998

\begin{abstract}
The effects of individual and neighborhood characteristics on relative FHAinsured mortgage applications and originations are examined. A sample of lowand moderate-income households drawn from the 1990 and 1991 Home Mortgage Disclosure Act is analyzed using census tract data. Although the relationship between relative FHA-insured mortgage activity and minority composition in a census tract is not significant, there is a negative relationship between median family income and FHA-insured mortgage activity controlling for individual characteristics of borrowers and some census tract characteristics. ๑ 1998 Academic Press
\end{abstract}

Several studies have examined the characteristics of borrowers of Federal Housing Administration (FHA) insured loans and neighborhoods that the FHA serves. These studies find that minorities are more likely to use FHA loans (Canner et al., 1991; Gabriel and Rosenthal, 1991); FHA mortgage activity is higher in central cities and low-income neighborhoods than in other neighborhoods (MacRae et al., 1982; Barth et al., 1983). However, these studies have left some questions unanswered. First, ex post data are used in their analyses. Therefore, it is not clear whether minorities are more likely to get FHA loans because they demand more FHA loans or because they are more likely to be denied for conventional loans. It is known that minorities are exposed to FHA loans more often than whites (Yinger, 1991). Second, since FHA loans are assumable, studies based on loans that home owners actually have, rather than those that they selected at the time of purchase, may reflect effects other than mortgage choice. Third, previous studies that examine the effect of indivdual and neighborhood characteristics on FHA borrowing are not very comprehensive. In

* I would like to thank Bob Avery for providing the data and for his guidance and comments. In addition, helpful comments are provided by Peter Zorn, Austin Kelly and David Burchfield. All remaining errors are mine alone. This study was supported by U.S. Department of Housing and Urban Development Dissertation Grant. 
general, they use either the American Housing Survey or the Survey of Consumer Finances. The former covers only a few MSAs and the latter samples mostly from relatively high-income households.

This study tries to eliminate some of the problems faced by the previous research in answering the empirical question of what markets and whom FHA mortgage insurance programs serve. First, the dataset used in this study is taken from the Home Mortgage Disclosure Act (HMDA) data which are most relevant U.S. observations. ${ }^{1}$ Second, it examines both mortgage applications (pre-approval demand) and mortgage originations (postapproval outcome) in order to identify whether mortgage applications for FHA loans differ from mortgage originations. Third, the empirical model tries to segregate the individual effects from the neighborhood effects.

Answering the question of what kind of people or neighborhoods the FHA serves will be useful for housing policy makers who decide continuity and availability of FHA-insured mortgage loans to these individuals and neighborhoods. Recent developments in the mortgage insurance market might jeopardize the continuity of the FHA's mortgage insurance programs. First, the FHA's losses were close to $\$ 6$ billion during the 1980s (Hendershoot and Waddell, 1992). Second, the Housing and Community Development Act of 1992 requires that a certain percentage of mortgages purchased by Government Sponsored Enterprises should be from central cities which are considered to be served by the FHA loans and for housing units occupied by families with income less than the median income (Weicher, 1994). Third, the Financial Institutions Reform, Recovery and Enforcement Act of 1989 requires Home Loan Banks to subsidize low income housing.

This study shows that although the relationship between relative FHAinsured mortgage activity and minority composition in a census tract is not significant, there is a negative relationship between median family income and FHA-insured mortgage activity controlling for individual characteristics of borrowers and some census tract characteristics. In addition, the results suggest that high black FHA loan originations can be explained by the high black FHA application.

This paper is organized as follows. The next section discusses previous studies examining the characteristics of FHA borrowers and their neighbor-

${ }^{1}$ Depository institutions, their direct subsidiaries and saving and loan associations and mortgage lending institutions with assets exceeding $\$ 10$ million are required to report their mortgage activities according to the HMDA reporting requirements. However, there is a debate about the coverage of the HMDA dataset. For example, comparing the loans purchased by Freddie Mac with the loans sold to Freddie Mac as reported in the 1992 HMDA dataset, Berkovec and Zorn (1996) estimate that the 1992 HMDA dataset contains only 70 percent of the total loans purchased by Freddie Mac even though the coverage of mortgage institutions are expanded at the end of 1991. In addition, their results show that the HMDA coverage rate is higher in the lower income census tracts relative to the higher income census tracts. 
hoods. The third section explains the empirical model and the data used. The results of the analysis and the conclusion follow.

\section{BACKGROUND}

The aim of the FHA is to increase home ownership among low- and moderate-income households by insuring home mortgages with low downpayments. $^{2}$ In order to achieve this objective, home buyers are required to pay mortgage insurance to the FHA. In return, lenders are $100 \%$ protected in the case of default on the part of the borrower. Since the FHA requires a lower downpayment and is more flexible in terms of other liquidity conditions, ${ }^{3}$ liquidity-constrained and riskier borrowers are expected to receive more FHA loans than conventional loans relative to less risky borrowers (Gabriel and Rosenthal, 1991).

In the mortgage choice literature, it is generally argued that individual borrowers maximize their expected utilities given their budget sets and wealth. Individuals who do not have enough down payment or who are constrained by the underwriting requirements of the private mortgage insurance companies are found to be more likely to choose an FHA loan relative to a conventional loan (for example, see Hendershoot and LaFayette, 1994). Theoretically, Brueckner (1985) shows that those borrowers who get higher utility from current consumption are more likely to get an FHA loan. However, although Bruecker assumes a competitive and homogeneous mortgage market in his model, the real mortgage market is not homogeneous; the lenders would offer different mortgages at different rates to their borrowers, depending on their riskiness. Therefore, each borrower faces a different choice set, depending on a borrower's riskiness or on other factors.

It can be argued that lenders originate different mortgages based on the riskiness of an applicant. If the mortgage applicant is riskier, lenders can credit ration their customers either by increasing the interest rate on the

${ }^{2}$ An individual borrower can get a mortgage without insurance if the loan-to-value (LTV) ratio is below 0.80 . If LTV ratio is above 0.80 , lenders require borrowers to procure mortgage insurance which affords protection to lenders in case of a default of an individual borrower. Private mortgage insurance companies generally do not insure mortgages with LTV ratios above 0.95 . If they do, they price them to reflect additional risk. However, during the years of this study, through the FHA, it was possible to get FHA-insured mortgages with high LTV ratios.

${ }^{3}$ For example, according to the government sponsored enterprises' underwriting requirements, the monthly payment for mortgage principal, interest, taxes and insurance must be less than $28 \%$ of the monthly gross income. According to the FHA, total housing expenses to net income ratio should be 0.36 . 
conventional loan or by deciding not to provide the conventional loan to those borrowers. Duca and Rosenthal (1991) show that the FHA share of mortgage origination increases as the aggegate default risk increases. A study by Yinger (1991) has found that blacks and other minorities are more likely than whites to be notified about the availability of FHA-insured mortgages. The results of previous studies that blacks are more likely to get an FHA loan (for example, Gabriel and Rosenthal, 1991; Canner et al., 1991) might be explained by the idea that blacks are more likely to apply for an FHA loan. Then, the results would not be because of a high mortgage denial rate but rather because of a high FHA application rate by black households. In addition, since the FHA provides $100 \%$ insurance to lenders in the case of a default by the borrower, lenders have an incentive to originate FHA loans relative to conventional loans when the default risk for a borrower is high.

There is a correlation between the individual characteristics and the neighborhood characteristics in which an individual lives. For example, Gabriel and Rosenthal (1989) show that there is a tendency among minorities to live in minority neighborhoods. It implies that not only individual characteristics but also neighborhood characteristics may affect the type of loan applied for or received. However, most of the previous studies examining the effect of neighborhood characteristics on FHA mortgage activity do not control for individual factors (for example, MacRae et al., 1982; Megbolugbe et al., 1994). Therefore, it is not possible to conclude whether blacks are more likely to get FHA loans because they are black, live in neighborhoods with growing minority population, or live in central cities, or are more likely to apply for the FHA-insured loans. Although Canner et al. (1991) control for some neighborhood characteristics in the analysis of the probability of getting a conventional loan, their sample is very small.

This study investigates the effect of neighborhood characteristics on relative FHA mortgage activity by controlling for the individual mortgage applicant's characteristics. In addition, it examines the effect of individual characteristics on mortgage applications and originations between FHAinsured and conventional loans by controlling for neighborhood characteristics. The next section explains the empirical model used in this study.

\section{EMPIRICAL MODEL}

The current literature on the mortgage choice between FHA and conventional loans suggests that the factors affecting the mortgage choice can be basically grouped into two categories: individual and neighborhood characteristics. Individual factors include race, default risk, liquidity condition, age, available wealth of an individual, and value of a house. All affect the type of mortgage that an individual can receive. Neighborhood 
characteristics include demographic factors such as racial composition, economic factors, housing characteristics, FHA loan limit, and availability of alternative mortgage instruments or mortgage programs in the neighborhood. So, in the analysis of what markets and what individuals the FHA serves, both individual and neighborhood factors should be included in the model. Given this information, the general model for an individual's choice for an FHA loan can be written

$$
P(\text { FHA } \mid \text { apply for a mortgage })_{i}=f\left(X_{\mathrm{I} i}, X_{\mathrm{N} i}\right),
$$

where $P(\text { FHA } \mid \text { apply for a mortgage })_{i}$ is the probability than an individual $i$ applies for an FHA loan given that an individual $i$ applied for a mortgage. $X_{\mathrm{I} i}$ and $X_{\mathrm{N} i}$ represent the characteristics of individual $i$ and the characteristics of the neighborhood where individual $i$ lives, respectively.

A variety of functional forms can be used to present the relationship in equation (1). A linear probability model is selected as a specification for this equation because of the size of the HMDA data,

$$
P\left(\mathrm{FHA} \mid X_{\mathrm{I}}, X_{\mathrm{N}}\right)_{i}=\alpha_{0}+X_{\mathrm{I} i} \alpha_{1}+X_{\mathrm{N} i} \alpha_{2}+e_{i},
$$

where $P\left(\mathrm{FHA} \mid X_{\mathrm{I}}, X_{\mathrm{N}}\right)_{i}$ is the conditional probability that individual $i$ will apply for an FHA loan given individual and neighborhood characteristics. If the error term in the regression equation, $e_{i}$, meets the assumptions of the classical regression model, the coefficients in Eq. (2) can be estimated consistently. If data on $X_{\mathrm{I}}$ and $X_{\mathrm{N}}$ were available, all of the apparatus of the classical model would apply. However, in reality, some of the variables that are represented by $X_{\mathrm{I}}$ and $X_{\mathrm{N}}$ are not available and may have only crude proxies. Thus, the actual variables can be expressed as a combination of observed variables and error terms,

$$
\begin{aligned}
X_{\mathrm{I} i} & =\text { INDIVIDUAL }_{i}+e_{\mathrm{I} i} \\
X_{\mathrm{N} n} & =\text { NEIGHBORHOOD }_{n}+e_{\mathrm{N} n},
\end{aligned}
$$

where INDIVIDUAL $\mathrm{I}_{i}$ represents a vector of characteristics of individual $i$, reported in the HMDA data, which are used as proxies for the actual variables, $X_{I}$. Similarly, NEIGHBORHOOD ${ }_{n}$ represents a vector of characteristics of neighborhoods available from the 1980 and 1990 U.S. Censuses that are used as proxies for the actual neighborhood characteristics, $X_{\mathrm{N}} \cdot e_{\mathrm{I} i}$ and $e_{\mathrm{N} n}$ are the error terms since INDIVIDUAL INd NEIGHBORHOOD $_{n}$ are only proxies for the actual variables. Thus, Eq. (2) can be written

$P\left(\text { FHA } \mid X_{\mathrm{I}}, X_{\mathrm{N}}\right)_{i}=\alpha_{0}+$ INDIVIDUAL $_{i} \alpha_{1}+$ NEIGHBORHOOD $_{i} \alpha_{2}+u_{i}$, 
where $u_{i}=e_{i}-\alpha_{1} e_{\mathrm{I} i}-\alpha_{2} e_{\mathrm{N} i}$. Since INDIVIDUAL I $_{i}$ and NEIGHBOR$\mathrm{HOOD}_{i}$ are correlated with error terms, one of the central assumptions of the classical regression model is violated and the least squares estimation will not provide consistent estimates. In order to get consistent estimates, a two-stage estimation mechanism is used in the analysis, ${ }^{4}$

Step I: $P\left(\mathrm{FHA} \mid X_{\mathrm{I}}, X_{\mathrm{N}}\right)_{i n}=\alpha_{0}^{*}+\alpha_{\mathrm{I}}^{*} \operatorname{INDIVIDUAL~}_{i}+\sum_{n=1}^{N} \beta_{n} D_{i n}+e_{i n}^{*}$

$$
\text { Step II: } \hat{\beta}_{n}=\delta_{0}^{*}+\delta_{\mathrm{N}}^{*} \mathrm{NEIGHBORHOOD}{ }_{n}+e_{n}^{*} \text {, }
$$

where $D_{\text {in }}$ is a vector of dummy variables indicating the census tract $n$ where the loan application of an individual $i$ is located and $\hat{\beta}_{n}$ represents the fixed effect coefficient on neighborhood $n$ estimated from the regression equation in the first step. The consistent estimates of the coefficients on individual characteristics are obtained from the fixed effects model in the first stage. ${ }^{5}$ The second step is estimated at the neighborhood level. The estimated fixed effect coefficient in the first stage is used as a dependent variable in the second stage. It is regressed against neighborhood characteristics.

Two-stage analysis with the fixed effects model provides the benefit of getting pure effects at each level. For example, estimation at the individual level disentangles neighborhood effects. In addition to getting consistent estimates, another reason for the selection of two-stage analysis is that given the size of the HMDA data, it was impossible to estimate the model specified in Eq. (2). However, there is a disadvantage of getting biased estimates of standard errors. The next discussion presents the variables used in the estimation in each stage.

\section{First Stage: Individual Level}

In the first stage, it is assumed that an individual's mortgage application can be expressed as a function of some individual characteristics, such as income, race, sex, existence of a co-applicant, and neighborhood (census tract). A linear probability model is estimated at the individual level with the census tract fixed effects,

${ }^{4}$ This mechanism will eliminate the problem of getting inconsistent estimates due to the correlation between $X_{\mathrm{I}}$ and $e_{\mathrm{N}}$, or the correlation between $X_{\mathrm{N}}$ and $e_{\mathrm{I}}$. The problem of getting inconsistent estimates due to measurement errors still holds. For more detailed information on two-stage procedure, see Avery et al. (1993, 1994).

${ }^{5}$ The coefficients are consistent because including dummy variables for each neighborhood in the model makes the error terms exclude any unobserved or observed neighborhood effects from the estimated coefficients on individual variables. 


$$
\text { Step I: } P(\mathrm{FHA})_{i n}=\sum_{n=1}^{N} \beta_{n} D_{n i}+\operatorname{INDIVIDUAL~}_{i n} \alpha_{\mathrm{I}}+e_{i n}^{*},
$$

where $P(\mathrm{FHA})_{i n}$ is operationalized to be 1 if an individual $i$, in a census tract $n$, is applying for or getting an FHA loan; it is 0 if the loan is a conventional loan. It is a conditional probability of applying for an FHA loan given that an individual applies for a mortgage. INDIVIDUAL ${ }_{i n}$ represents a vector of an individual $i$ 's characteristics living in a neighborhood $n$. The individual variables include the existence of a co-applicant, the sex, income, and race of an applicant, and those of a co-applicant. Ideally, more individual characteristics such as wealth, credit rating, age, and risk of an individual borrower need to be controlled for in the mortgage application process. However, the HMDA dataset does not provide such information. Therefore, only those individual characteristics reported in the HMDA dataset are included in the model. A reduced form model is estimated with income and some demographic characteristics of the individual applicant since the loan amount is endogeneous because of the FHA loan limit. It is known that the income level of some minority groups is different from that of whites. Therefore, the interaction variables for race and income are also included in the model.

\section{Second Stage: Neighborhood (Census Tract) Level}

The second stage is the estimation at the census tract level. The dependent variable in this stage is the fixed effect coefficient on each census tract dummy variable, estimated in the first stage. In other words, it is a part of FHA activity that is not explained by individual factors aggregated at the census tract level. Thus, the dependent variable is

$$
\text { Fixed effect coefficient }=\hat{\beta}_{n}=\overline{\mathrm{FHA}}_{n}-\overline{\mathrm{INDIVIDUAL}}_{n} \hat{\alpha}_{\mathrm{I}},
$$

where $\overline{\mathrm{FHA}}_{n}$ is the observed percentage of FHA-insured applications in census tract $n\left(\overline{\mathrm{FHA}}_{n}=\left(\sum_{i=1}^{N_{n}} \mathrm{FHA}_{i n}\right) / N_{n}\right.$, where $N_{n}$ is the number of individual applications in census tract $n$ and $\mathrm{FHA}_{i n}$ is 1 if it is an FHA loan), $\overline{\text { INDIVIDUAL }}_{n}$ is the average of each individual variable in tract $n\left(\overline{\text { INDIVIDUAL }}_{n}=\left(\sum_{i=1}^{N_{n}}\right.\right.$ INDIVIDUAL $\left.\left._{i n}\right) / N_{n}\right)$, and $\hat{\alpha}_{1}$ represents the estimated coefficients on each individual variable in the first step.

In the second stage, these neighborhood residuals are regressed on the various neighborhood characteristics. Two models are estimated in this stage,

Model I: $\hat{\beta}_{n}=\delta+$ NEIGHBORHOOD ${ }_{n} \delta_{N}+e_{n}$

Model II: $\hat{\beta}_{n}=\sum_{m=1}^{M} \delta_{m} D_{m}+$ NEIGHBORHOOD ${ }_{n} \delta_{N}+e_{n}$, 
where $\mathrm{NEIGHBORHOOD}_{n}$ represents the variables representing the neighborhood characteristics in the census tract $n . D_{m}$ represents dummy variables indicating an MSA $m$ where a census tract $n$ is located. Model I assumes that it is the tract characteristics that count (within and between MSA variation). It shows the general effect of neighborhood characteristics on the probability of applying for or getting an FHA loan. Model II answers how neighborhood characteristics affect the probability of applying for or getting an FHA loan within the same MSA because some of the variation in FHA activity among neighborhoods can be attributed to the MSA characteristics such as FHA loan limit (within MSA variation).

The neighborhood characteristics are grouped into three categories: demographic characteristics, economic characteristics and housing market characteristics. Demographic characteristics include the minority percentage of residents in the neighborhood, the change in minority share from 1980 to 1990, and the age distribution of the household heads. Minority shares in neighborhood in 1990 are represented with splines ${ }^{6}$ in order to identify the effect of the different levels of minority shares in the census tract. In addition, the changes in minority shares from 1980 to 1990 are represented with dummy variables. An age of an individual applicant is approximated by the distribution of age of household heads in the neighborhood in 1990. In order to control for the size of the housing unit that an individual borrower will buy, the average household size for the owneroccupied units is also included in the model. The bigger the household, the more likely it is to demand a larger (more expensive) house, and the less likely to apply for and get an FHA loan, because of the FHA loan limit.

Economic characteristics are represented by median family income, its splines, and the dummy variables representing the percentage change in median family income from 1980 to 1990 . A study by MacRae et al. (1983) finds a quadratic relationship between FHA activity and median income level in a neighborhood. A nonlinear relationship is imposed in the model with median family income splines.

Housing market characteristics include the distribution of housing units in terms of the number of units in structure, the housing occupancy variables, the change in housing occupancy variables during the decade from 1980 to 1990, and the age distribution of housing units. It can be hypothesized that if the vacancy or rental rate is high in the neighborhood, the probability of deterioration is also high, and FHA activity will be high. In addition, if the percentage of older houses in the neighborhood is high, the probability of getting an FHA loan is expected to be high. Housing occupancy is measured by the rental and vacancy rates in 1990 and the change

${ }^{6}$ Throughout the range of values of minority share, the probability of getting an FHA loan might be rising, but the slope might change at some percentages. One could fit the regression model by dividing the sample into subsamples and use dummy variables. However, this would neglect the continuity of the function. Instead, a spline function is applied. 
in these rates during the past decade. Since the FHA provides mortgage insurance for one- to four-family units, the rental rate, vacancy rate, and change in these rates are considered only for 1-4 housing units. The growth rate in total housing units is included in the model in order to control for the general economic conditions. The age of housing stock is approximated by the percentage of housing units built in different time periods. Previous studies find that FHA activity is high in central cities, and these areas are found to be underserved by conventional mortgage lenders. A central city dummy variable is added to the model. The next section describes the data.

\section{DATA}

Only owner-occupied new home purchase mortgage applicants are included in the sample because a borrower has to be an owner-occupant to get an FHA loan. The sample includes only those households that have income less than or equal to $120 \%$ of the median family income in the corresponding Metropolitan Statistical Area (MSA). They can be considered as representing low- and moderate-income households which are aimed to be served by the FHA.

\section{Mortgage Applications and Originations}

Individual level data are obtained from the Home Mortgage Disclosure Act (HMDA) data. According to this Act, the depository institutions (commercial banks, savings and loan associations, savings banks and credit unions), their direct subsidiaries, and other unaffiliated mortgage lending institutions with assets more than $\$ 10$ million (Canner and Gabriel, 1992) are required to provide information about their mortgage applicants. The data have the highest coverage of mortgage applications in the United States. ${ }^{7}$

In this study, two years of HMDA datasets are used, 1990 and 1991. All mortgages are divided into two groups: FHA loans and conventional loans. In this study, all other loans that are not insured by the FHA are classified as conventional loans. They include state mortgage programs, privately insured loans and uninsured loans. The Veterans Administration (VA) and Farmers Home Association (FmHA) insured loans are not included in the sample.

Some characteristics of the applicants in the sample are presented in Table I. The samples from the 1990 and 1991 HMDA datasets show similar characteristics. The percentage of FHA-insured loans is higher than normal because of the elimination of high-income applicants and borrowers. The

${ }^{7}$ During 1990 and 1991, the HMDA did not require smaller mortgage bankers to report their mortgage activities. Hence, the exclusion of the smaller mortgage bankers from the dataset will result in the underrepresentation of FHA loans. According to Berkovec and Zorn (1996), the HMDA dataset for 1992 is estimated to contain only $65 \%$ of total mortgage loans. 
percentage of FHA-insured mortgage applicants who are black is 13.3 (13.1) in 1990 (1991). ${ }^{8}$ However, the percentage of conventional loan applicants who are black is only 5.8 (5.3). The black percentages decline slightly for originations: $11.2 \%$ (11.3\%) of FHA-insured mortgage borrowers and 4.6\% (4.2\%) of conventional loan borrowers are black. The denial rates on FHA loans are lower than the conventional loans: $15.8 \%(15.7 \%)$ versus $20.7 \%$ (21.9\%) percent. Although the median loan amount and loan-to-income ratio for FHA loans are higher than those for conventional loans because of higher allowable LTV ratios, median incomes of FHA applicants and borrowers are slightly lower than those for conventional loan borrowers.

\section{Neighborhood Characteristics}

The neighborhood data are obtained from the 1980 and the 1990 U.S. Censuses. In this study, neighborhood and census tract are used interchangeably. Rural census tracts and census tracts with zero population (either in 1990 or in 1980) or those with nonpositive median house values, nonpositive median family income, or less than 50 total housing units (in either 1980 or in 1990) are excluded from the sample. ${ }^{9}$

Table II shows the FHA application and origination rates of census tracts on the basis of several neighborhood characteristics weighted by the number of mortgage applications or mortgage originations in each neighborhood. According to the HMDA data and the U.S. Census, FHA application and FHA origination rates are higher in central cities and in more minority-populated, low income, low house value, and high-risk neighborhoods, i.e., those neighborhoods with low growth rates in median house value and in median family income from 1980 to 1990 . The descriptive statistics of the census tract characteristics included in the model are presented in the Appendix.

\section{RESULTS}

\section{Individual Characteristics}

Mortgage Applications. The results of the linear probability model with neighborhood fixed effects for individual mortgage applications in 1990 and 1991 are presented in Table III. They are similar in both years. Dramatic

\footnotetext{
${ }^{8}$ The figures in parentheses throughout the paper represent the corresponding figures in 1991.

${ }^{9}$ The characteristics of neighborhoods where the lender is located are used as an approximation for the individual borrower's neighborhood characteristics because HMDA dataset provides the location of the loan. Another limitation is that the 1990 and 1991 HMDA data use 1980 census tract definitions. The census tract definitions used in 1990 Census are different from the ones used in the 1980 Census. A common unit of analysis is needed in combining these data sets. Claritas converted the 1990 Census data into 1980 census tract definitions. Therefore, the 1990 Census data provided by Claritas are used in the analysis. Hence, the variables used in the second stage are only available from Claritas.
} 


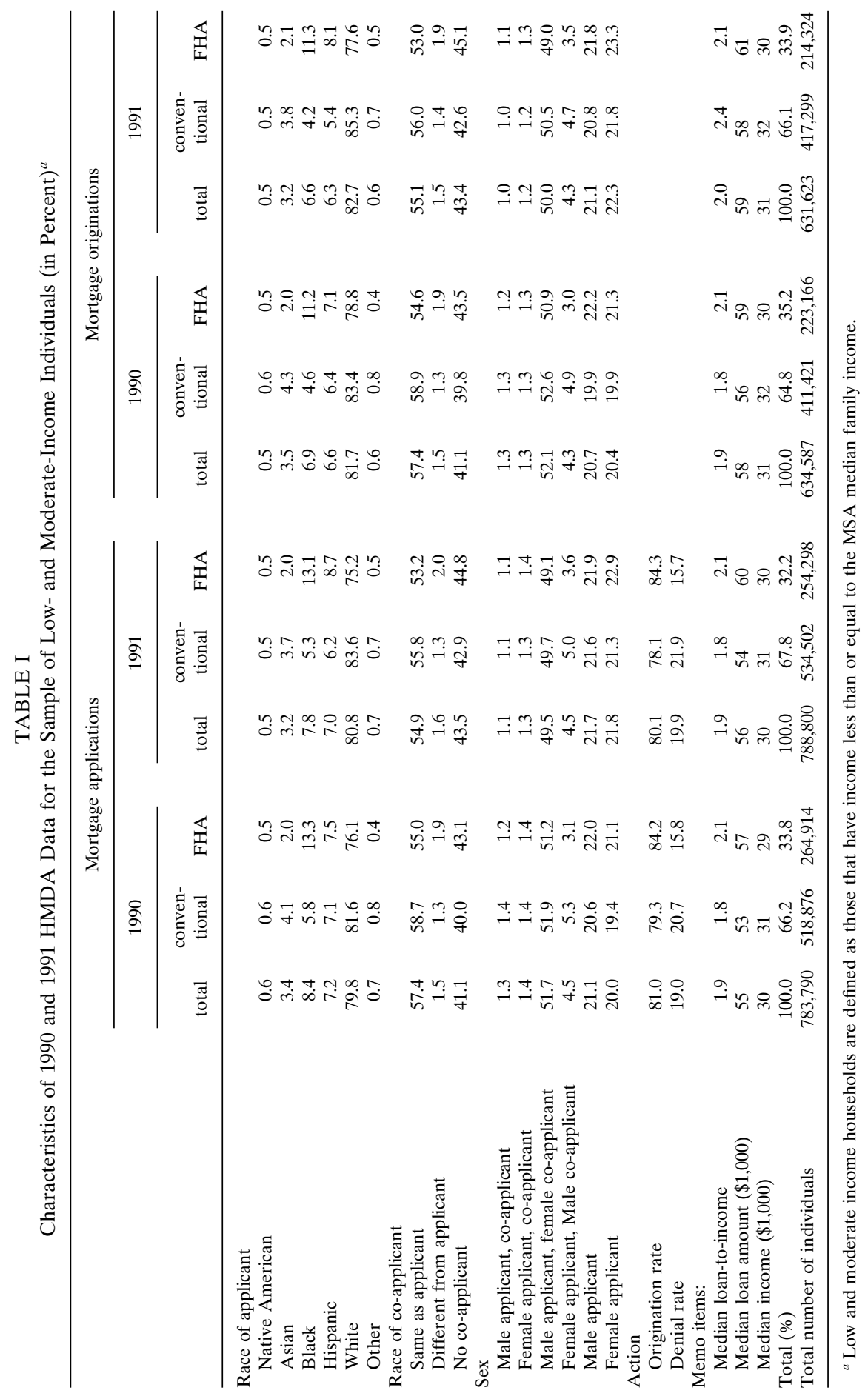


TABLE II

Weighted Mean FHA Application and Origination Rates with Respect to Census Tract Characteristics

\begin{tabular}{|c|c|c|c|c|}
\hline & \multicolumn{2}{|c|}{ Application } & \multicolumn{2}{|c|}{ Origination } \\
\hline & 1990 & 1991 & 1990 & 1991 \\
\hline \multicolumn{5}{|c|}{ Characteristics of neighborhoods } \\
\hline Non-central-city & 0.2845 & 0.2727 & 0.2982 & 0.2898 \\
\hline Central city & 0.4109 & 0.3937 & 0.4272 & 0.4125 \\
\hline \multicolumn{5}{|l|}{ Minority share } \\
\hline $0.00-0.05$ & 0.2685 & 0.2404 & 0.2804 & 0.2554 \\
\hline $0.05-0.10$ & 0.3343 & 0.3078 & 0.3475 & 0.3210 \\
\hline $0.10-0.25$ & 0.3746 & 0.3629 & 0.3938 & 0.3858 \\
\hline $0.25-0.50$ & 0.3966 & 0.3946 & 0.4180 & 0.4222 \\
\hline $0.50-$ & 0.3778 & 0.3955 & 0.3918 & 0.4226 \\
\hline \multicolumn{5}{|c|}{ Change in minority share } \\
\hline Less than 0.00 & 0.2949 & 0.2650 & 0.3136 & 0.2878 \\
\hline $0.00-0.05$ & 0.3131 & 0.2921 & 0.3253 & 0.3066 \\
\hline $0.05-0.10$ & 0.3740 & 0.3641 & 0.3916 & 0.3859 \\
\hline $0.10-0.15$ & 0.3808 & 0.3937 & 0.3988 & 0.4192 \\
\hline $0.15-$ & 0.4329 & 0.4459 & 0.4485 & 0.4692 \\
\hline \multicolumn{5}{|l|}{ Median income } \\
\hline Less than $\$ 20,000$ & 0.3948 & 0.3765 & 0.4191 & 0.4150 \\
\hline$\$ 20,000-\$ 40,000$ & 0.3771 & 0.3601 & 0.3990 & 0.3865 \\
\hline$\$ 40,000-\$ 60,000$ & 0.3011 & 0.2924 & 0.3107 & 0.3032 \\
\hline$\$ 60,000-\$ 80,000$ & 0.1814 & 0.1657 & 0.1868 & 0.1718 \\
\hline$\$ 80,000-\$ 100,000$ & 0.1110 & 0.0987 & 0.1152 & 0.0985 \\
\hline$\$ 100,000-$ & 0.0751 & 0.0548 & 0.0792 & 0.0585 \\
\hline \multicolumn{5}{|c|}{ Change in median income } \\
\hline Less than $0 \%$ & 0.3655 & 0.3423 & 0.3923 & 0.3772 \\
\hline $0-25 \%$ & 0.4773 & 0.4331 & 0.5012 & 0.4637 \\
\hline $25-50 \%$ & 0.4632 & 0.4426 & 0.4892 & 0.4739 \\
\hline $50-100 \%$ & 0.3463 & 0.3303 & 0.3614 & 0.3484 \\
\hline $100-150 \%$ & 0.2138 & 0.2125 & 0.2236 & 0.2238 \\
\hline $150 \%-$ & 0.2118 & 0.2090 & 0.2227 & 0.2234 \\
\hline \multicolumn{5}{|l|}{ Median house value } \\
\hline Less than $\$ 25,000$ & 0.3607 & 0.3303 & 0.3866 & 0.3562 \\
\hline$\$ 25,000-\$ 50,000$ & 0.4524 & 0.4113 & 0.4796 & 0.4429 \\
\hline$\$ 50,000-\$ 75,000$ & 0.4242 & 0.3936 & 0.4455 & 0.4196 \\
\hline$\$ 75,000-\$ 100,000$ & 0.3706 & 0.3613 & 0.3858 & 0.3767 \\
\hline$\$ 100,000-\$ 150,000$ & 0.2681 & 0.2796 & 0.2808 & 0.2925 \\
\hline$\$ 150,000-$ & 0.1064 & 0.1140 & 0.1139 & 0.1237 \\
\hline \multicolumn{5}{|c|}{ Change in median house value } \\
\hline Less than $0 \%$ & 0.4646 & 0.4004 & 0.4815 & 0.4217 \\
\hline $0-25 \%$ & 0.4787 & 0.4480 & 0.4924 & 0.4629 \\
\hline $25-50 \%$ & 0.4067 & 0.3763 & 0.4228 & 0.3929 \\
\hline $50-100 \%$ & 0.3570 & 0.3374 & 0.3729 & 0.3590 \\
\hline $100-150 \%$ & 0.2418 & 0.2403 & 0.2562 & 0.2599 \\
\hline $150 \%-$ & 0.1104 & 0.1240 & 0.1161 & 0.1308 \\
\hline
\end{tabular}


racial differences between black and white mortgage applicants are observed in the analysis of low- and moderate-income mortgage applicants. Blacks were $12.61 \%(12.28 \%)$ more likely to apply for an FHA loan than white applicants in 1990 (1991), controlling for their income, sex, and coapplicant and the census tract where they applied for a mortgage. The difference is found to be less for other racial groups. For example, Hispanics are $8.01 \%(9.37 \%)$ more likely to apply for an FHA loan, but Native Americans are $2.25 \%(4.88 \%)$ less likely to apply for FHA loans than their white counterparts. No significant difference was found between Asian and white applicants.

There are several explanations as to why blacks are more likely to apply for FHA loans than their white counterparts. One explanation is that they are more likely to be exposed to FHA loans than whites, as reported by Yinger (1991). A second explanation is that there may be prescreening by lenders or by an individual applicant, which leads to more FHA applications because of the higher possibility of rejection with conventional loans. Third, in general, the relative wealth of blacks is less than that of whites,${ }^{10}$ and they are more likely to be liquidity-constrained than whites (Duca and Rosenthal, 1993 and 1994). Therefore, they may be more likely to apply for FHA loans than whites even though they have similar income levels. Unfortunately, the default risk and liquidity condition of applicants are not controlled for in this paper. ${ }^{11}$ Fourth, it can be argued that blacks are more likely to get smaller houses, requiring smaller loan amounts; hence, they are more likely to be eligible for FHA loans because of the FHA loan limit. ${ }^{12}$

${ }^{10}$ According to the 1989 Survey of Consumer Finances, the median total worth and the median total financial assets of white households are $\$ 58,500$ and $\$ 11,500$, respectively. For nonwhite households, these figures are $\$ 4,000$ and $\$ 2,000$, respectively (Kennickel and ShackMarquez, 1992).

${ }^{11}$ The same model is estimated for a sample of mortgage applicants that have income less than or equal to $80 \%$ of the MSA median family income. The difference still holds between white and black applicants. For example, black individuals are $11.6 \%$ (8.5\%) more likely to apply for FHA loans than white applicants with the same income and sex and in the same census tract.

${ }^{12}$ To answer the question of whether blacks are more likely to apply for FHA loans because of higher default risk or because of requiring smaller loan amounts, a similar model is estimated for a sample of applicants with loan amounts less than the FHA mortgage loan limit. In the estimation, it is assumed that the loan amount is exogenous. In addition to demographic characteristics, loan amount with splines and loan-amount-to-income ratio as a proxy for default risk are included in the model. Results are found to be similar. It is found that blacks are $9.8 \%$ (12.6\%) more likely to apply for an FHA-insured loan than their white counterparts; as the loan-to-income ratio increases, the probability of applying for an FHA loan increases; the black and white differences are found to be greater at higher income levels. For example, in 1991 , a black applicant with a $\$ 20,000$ income or a $\$ 120,000$ income is 13.3 or $18.5 \%$ more likely respectively, to apply for an FHA loan than a white applicant with the same characteristics. 
TABLE III

Linear Probability Model of FHA Application (1) or Conventional Application (0) for a Sample of Low and Moderate Income Applicants

(Model: $\left.P(\mathrm{FHA})_{i n}=\sum_{n=1}^{N} \beta_{n} D_{n i}+\operatorname{INDIVIDUAL}_{i n} \alpha_{\mathrm{I}}+e_{i n}^{*}\right)$

\begin{tabular}{cccc}
\hline $\begin{array}{c}\text { Parameter } \\
\text { estimate }\end{array}$ & & $\frac{1990}{\text { Parameter }}$ \\
estimate & $t$-value \\
\hline
\end{tabular}

Race of applicant, co-applicant

(base group: white)

Native American applicant

Asian applicant

Black applicant

Hispanic applicant

Other race applicant

White applicant, minority co-applicant

Minority applicant white co-applicant

$\begin{array}{rrrr}-0.0225 & -1.26 & -0.0488 & -2.63 \\ 0.0093 & 1.06 & -0.0050 & -0.54 \\ 0.1261 & 23.50 & 0.1228 & 22.12 \\ 0.0801 & 13.19 & 0.0937 & 15.37 \\ 0.0273 & 1.54 & -0.0203 & -1.12 \\ 0.1559 & 9.90 & 0.0611 & 3.78 \\ 0.0850 & 4.81 & 0.0972 & 5.61\end{array}$

Sex of applicant and co-applicant

(base group: female applicant)

Male applicant, female co-applicant

$\begin{array}{rrrr}0.0758 & 5.05 & 0.0222 & 1.31 \\ 0.0088 & 0.58 & -0.0263 & -1.54 \\ 0.0845 & 5.45 & 0.0369 & 2.11 \\ 0.0674 & 4.36 & 0.0192 & 1.11 \\ 0.0100 & 6.91 & 0.0075 & 5.33\end{array}$

Female applicant, male co-applicant

Male applicant, co-applicant

Female applicant, co-applicant

Male applicant

Income race interaction variables

White

0.0169

20.29

0.0155

15.75

Native American

0.0169

16.83

0.0166

14.57

0.0157

18.12

0.0146

14.41

Black

Hispanic

0.0167

19.70

0.0158

15.88

0.0163

19.15

0.0151

15.13

Other race

0.0158

16.19

0.0154

13.85

0.0147

15.54

0.0150

13.89

0.0168

17.21

0.0149

13.50

Income splines $(\$ 1,000)$

Income spline at $\$ 15,000$

Income spline at $\$ 20,000$

Income spline at $\$ 25,000$

Income spline at $\$ 30,000$

$-0.0092$

$-6.31$

$-0.0074$

$-4.59$

$-0.0004$

$-0.26$

$-0.0008$

$-0.57$

0.0009

0.78

$-0.0008$

$-0.67$

$-0.0111$

$-10.87$

$-0.0075$

$-7.18$

0.0043

4.18

0.0030

2.88

Income spline at $\$ 40,000$

Income spline at $\$ 45,000$

$-0.0034$

$-2.95$

$-0.0048$

$-4.17$

$-0.0038$

$-4.34$

$-2.73$

Income and no co-applicant

interaction variables

Income

Income spline at $\$ 15,000$

Income spline at $\$ 20,000$

Income spline at $\$ 25,000$

Income spline at $\$ 30,000$

Income spline at $\$ 35,000$

Income spline at $\$ 40,000$

Income spline at $\$ 45,000$

$\begin{array}{rrrr}0.0050 & 4.39 & 0.0009 & 0.74 \\ 0.0008 & 0.39 & 0.0043 & 2.05 \\ -0.0091 & -4.72 & -0.0056 & -2.87 \\ -0.0012 & -0.69 & -0.0043 & -2.57 \\ 0.0025 & 1.54 & 0.0033 & 2.06 \\ -0.0016 & -0.90 & -0.0050 & -2.89 \\ 0.0014 & 0.69 & 0.0062 & 3.13 \\ 0.0028 & 1.79 & 0.0004 & 0.29\end{array}$


TABLE III-Continued

\begin{tabular}{|c|c|c|c|c|}
\hline & \multicolumn{2}{|c|}{1990} & \multicolumn{2}{|c|}{1991} \\
\hline & $\begin{array}{l}\text { Parameter } \\
\text { estimate }\end{array}$ & $t$-value & $\begin{array}{c}\text { Parameter } \\
\text { estimate }\end{array}$ & $t$-value \\
\hline \multicolumn{5}{|l|}{ Memo items } \\
\hline Number of observations & 783,789 & & 788,799 & \\
\hline Number of census tracts & 38,008 & & 37,766 & \\
\hline$R$-squared & 0.3455 & & 0.3167 & \\
\hline Mean of the dependent variable & 0.3380 & & 0.3224 & \\
\hline
\end{tabular}

When the hypothesis that the effect of income is the same for all racial groups is tested, it is found that racial groups are not significantly different. The results show that the differences between whites and blacks in terms of applying for an FHA loan do not change significantly as income level changes. For example, at income level $\$ 15,000$, blacks are $12.31 \%(12.31 \%)$ percent more likely than whites to apply for FHA loans. This difference is $13.78 \%$ (11.61\%) percent at the $\$ 50,000$ income level.

Mortgage Originations. A similar model is estimated for mortgage originations to examine whether individual factors affect mortgage originations and mortgage applications differently. The results are found to be similar to those for the mortgage applications (Table IV).

Racial differences are also found with respect to mortgage originations. Blacks are $12.57 \%(12.21 \%)$ more likely to get an FHA loan than whites, and Hispanics are $8.52 \%(10.00 \%)$ percent more likely to get an FHA loan than whites. The difference is the probability of FHA origination between blacks and whites is slightly lower than the difference with FHA applications. The smaller difference between whites and blacks in terms of FHA mortgage originations suggests that whites' relative denial rate for conventional loans is higher than blacks' relative denial rate. According to the HMDA datasets, blacks are 1.96 (2.35) times more likely than whites to be denied conventional loans. The relative denial rate for FHA loans is higher: blacks are 2.26 times more likely than whites to be denied. ${ }^{13}$ Another possibility is that whites may be applying for higher loan amounts than other racial groups, leading to higher relative denial rates in conventional loans since loan amount is not included in this model. ${ }^{14}$

The effect of income level on mortgage originations is similar to that on

${ }^{13}$ According to the 1990 (1991) HMDA datasets, the black denial rates for conventional and FHA loans are $37.39 \%(31.5 \%)$ and $29.16 \%$ (28.10\%), respectively. The white denial rate is $19.03 \%(13.40 \%)$ for conventional loans and $12.86 \%(11.90 \%)$ for FHA loans.

${ }^{14}$ It is found that controlling for the loan amount and a proxy for default risk, blacks are $10.3 \%(13.3 \%)$ more likely to get an FHA loan than whites. 
TABLE IV

Linear Probability Model of FHA Origination (1) or Conventional Origination (0) for Borrowers with Income Less Than $\$ 50,000$

(Model: $\left.P(\mathrm{FHA})_{i n}=\sum_{n=1}^{N} \beta_{n} D_{n i}+\operatorname{INDIVIDUAL}_{i n} \alpha_{\mathrm{I}}+e_{i n}^{*}\right)$

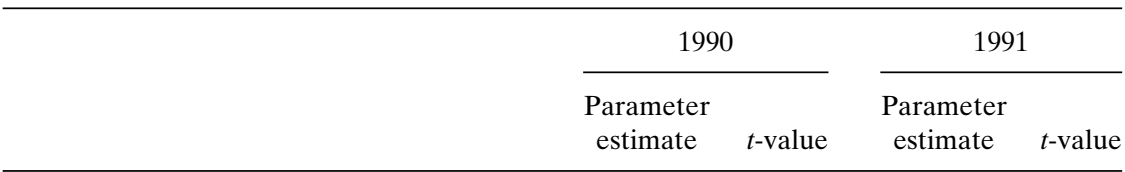

Race of applicant, co-applicant

(base group: white)

Native American applicant

Asian applicant

Black applicant

$-230$

$-0.0560$

$-2.45$

$-0.0160$

$-1.61$

$-0.0365$

$-3.45$

Hispanic applicant

0.1257

18.33

0.1221

17.14

0.0852

11.48

0.1000

13.25

Other race applicant

0.0124

0.59

$-0.0220$

$-1.01$

White applicant, minority co-applicant

0.1815

9.99

0.0504

2.66

Minority applicant, white co-applicant

0.1055

5.02

0.0939

4.45

Sex of applicant and co-applicant

(base group: female applicant)

Male applicant, female co-applicant

0.0769

3.65

0.0291

1.22

Female applicant, male co-applicant

0.0172

0.81

$-0.0118$

$-0.49$

0.0905

4.20

0.0575

2.35

Female applicant, co-applicant

0.0665

3.09

0.0284

1.17

Male applicant

0.0201

12.44

0.0169

10.51

Income race interaction variables

White

0.0167

14.59

0.0149

11.08

Native American

0.0172

13.05

0.0161

10.66

Asian

Black

Hispanic

0.0160

13.59

0.0146

10.62

0.0166

14.26

0.0161

13.79

0.0154

11.30

0.0158

12.23

0.0145

10.64

Other race

0.0139

0.0148

10.01

White applicant, minority co-applicant

0.0161

11.15

0.0146

10.15

Minority applicant, white co-applicant

12.53

0.0145

9.84

Income splines $(\$ 1,000)$

Income spline at $\$ 15,000$

Income spline at $\$ 20,000$

Income spline at $\$ 25,000$

Income spline at $\$ 30,000$

Income spline at $\$ 35,000$

Income spline at $\$ 40,000$

Income spline at $\$ 45,000$

$-0.0079$

$-4.16$

$-0.0050$

$-2.37$

$-0.0019$

$-1.11$

$-0.0041$

$-2.28$

0.0002

0.15

0.0004

0.30

$-0.0100$

$-8.80$

$-0.0078$

$-6.53$

0.0042

3.75

0.0030

2.55

$-0.0037$

$-2.95$

$-0.0047$

$-3.68$

$-0.0040$

$-4.21$

$-0.0025$

$-2.60$

Income and no co-applicant interaction variables

Income

Income spline at $\$ 15,000$

Income spline at $\$ 20,000$

Income spline at $\$ 25,000$

Income spline at $\$ 30,000$

Income spline at $\$ 35,000$

Income spline at $\$ 40,000$

Income spline at $\$ 45,000$

$\begin{array}{rrrr}0.0057 & 3.64 & 0.0020 & 1.14 \\ -0.0028 & -1.07 & 0.0008 & 0.28 \\ -0.0065 & -2.86 & -0.0032 & -1.36 \\ -0.0009 & -0.48 & -0.0049 & -2.49 \\ 0.0024 & 1.38 & 0.0038 & 2.11 \\ -0.0021 & -1.11 & -0.0044 & -2.35 \\ 0.0024 & 1.12 & 0.0056 & 2.60 \\ 0.0023 & 1.34 & 0.0006 & 0.34\end{array}$


TABLE IV-Continued

\begin{tabular}{|c|c|c|c|c|}
\hline & \multicolumn{2}{|c|}{1990} & \multicolumn{2}{|c|}{1991} \\
\hline & $\begin{array}{l}\text { Parameter } \\
\text { estimate }\end{array}$ & $t$-value & $\begin{array}{c}\text { Parameter } \\
\text { estimate }\end{array}$ & $t$-value \\
\hline \multicolumn{5}{|l|}{ Memo items } \\
\hline Number of observations & 634,586 & & 631,622 & \\
\hline Number of census tracts & 37,138 & & 36,871 & \\
\hline$R$-squared & 0.3622 & & 0.3295 & \\
\hline Mean of the dependent variable & 0.3517 & & 0.3393 & \\
\hline
\end{tabular}

mortgage applications. At income levels below $\$ 30,000$, income and the probability of FHA origination are positively correlated; at income levels above $\$ 30,000$, they are negatively correlated. At income level of $\$ 15,000$, blacks' probability of getting an FHA loan is $12.42 \%$ (12.96\%) higher than that of whites. This is $12.07 \%(14.71 \%)$ at the income level of $\$ 50,000$. The difference between whites and other racial groups at different income levels in terms of the expected probability of getting an FHA loan is similar to the differences in the expected probability of FHA applications. However, results do not explain why the results differ in two years. It may be because of policy changes or changes in the characteristics of white applicants.

The next section examines how neighborhood characteristics affect the individuals' probabilities of applying for and getting an FHA loan, controlling for individual characteristics.

\section{Neighborhood Characteristics}

Mortgage Applications. ${ }^{15}$ The estimations for FHA applications are presented in Table $\mathrm{V}$. The regression results show that the correlation between the probability of applying for an FHA loan and minority percentage in census tract is positive in less and highly minority-populated census tracts, but it is negative in moderately minority-populated census tracts. In addition, the probability of applying for an FHA loan is found to be positively correlated with the change in minority share over the last decade.

Results with respect to housing characteristics are similar to expectations.

\footnotetext{
${ }^{15}$ Three different dependent variables are used in the analysis of the effect of neighborhood characteristics on mortgage applications and originations: the 1990/1991 average of fixed census tract effects, the fixed census tract effects obtained from the 1990 estimates, and the fixed census tract effects obtained from the 1991 estimates. The results are similar for the years 1990 and 1991 and the averages of 1990 and 1991 figures weighted by the number of applications in each year. Only the results with the 1990-1991 averages are presented. The other estimations are available from the author upon request.
} 


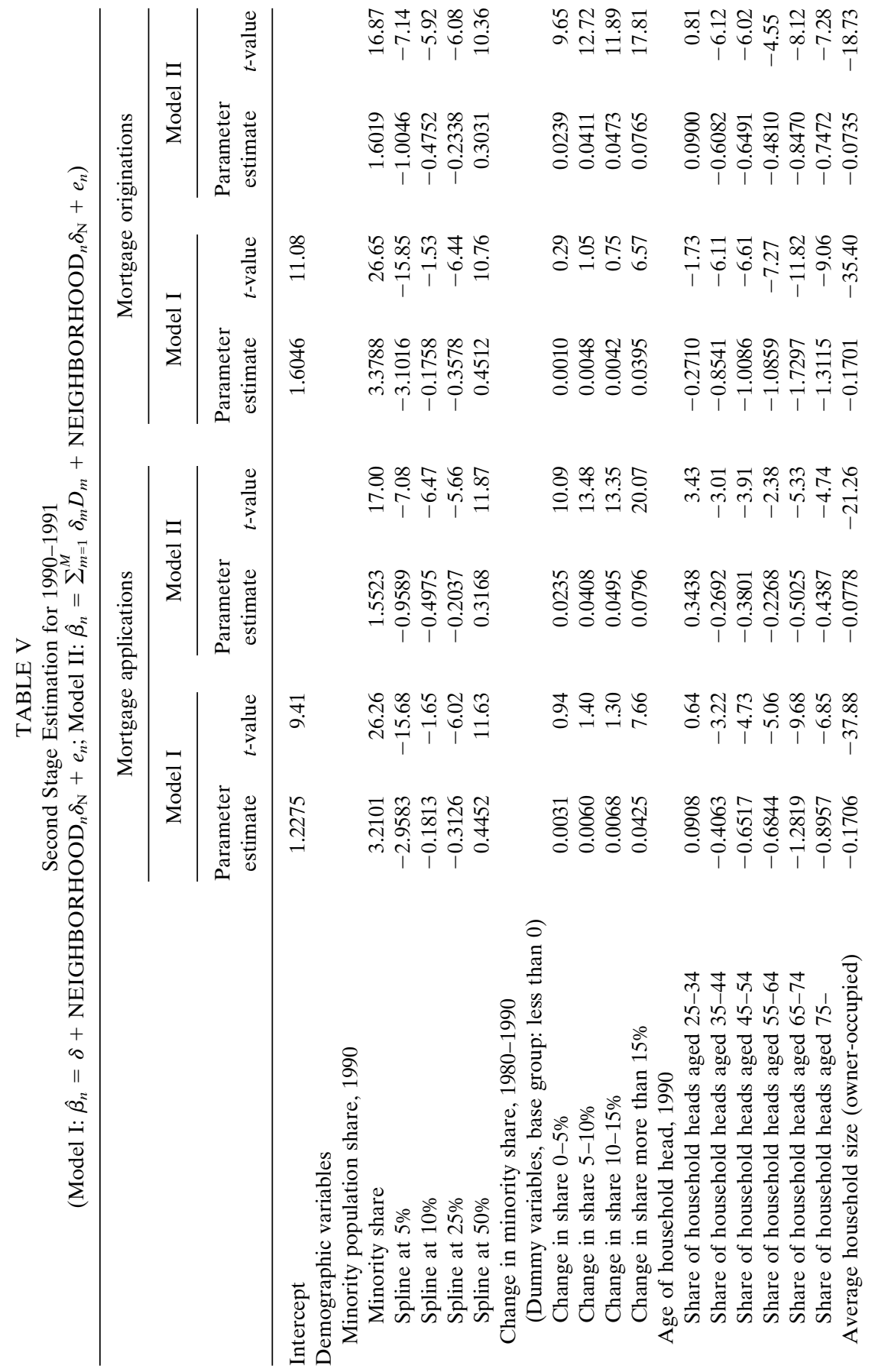




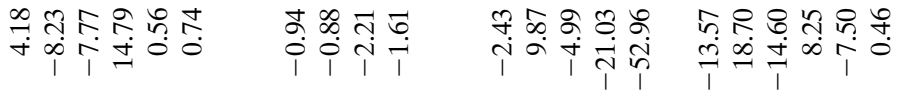

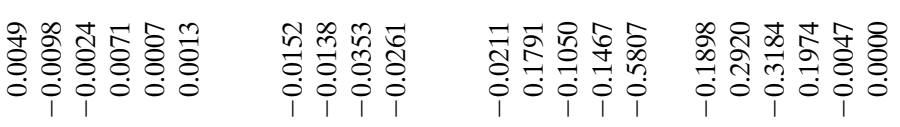

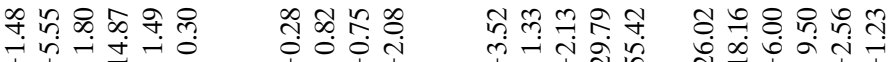

in

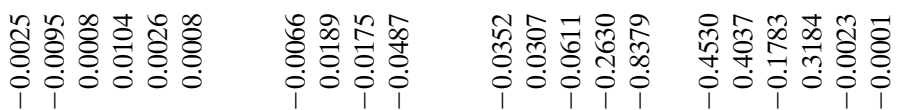

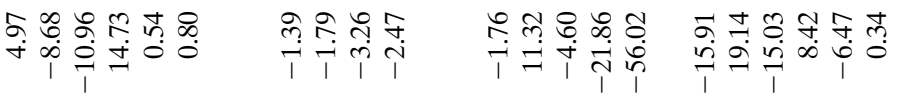

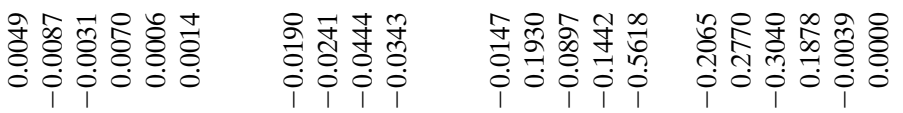

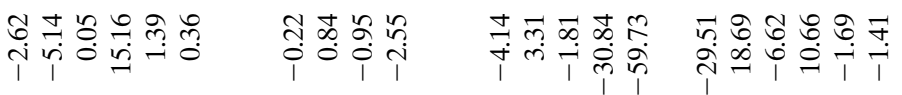

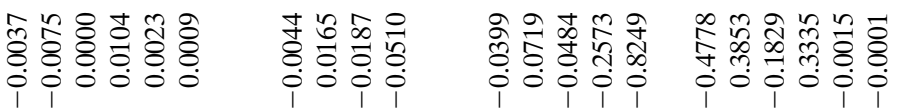

$\stackrel{8}{2}$

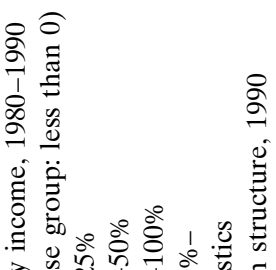

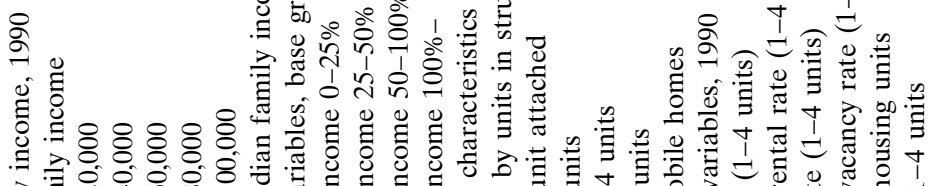

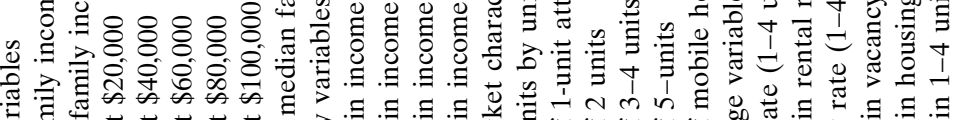

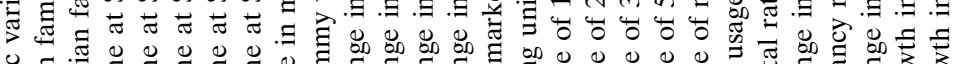

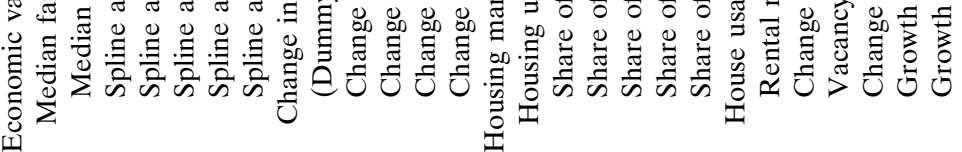




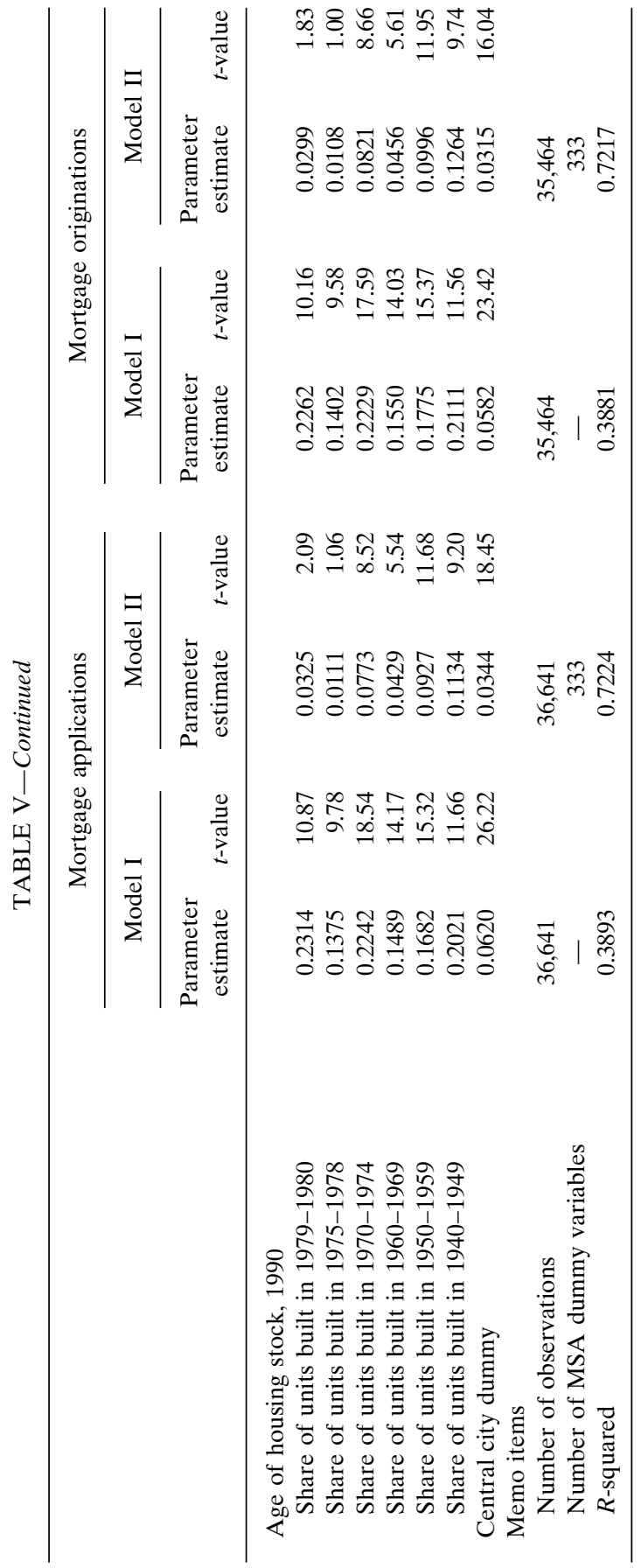


It is found that vacancy and rental rates on one-to-four housing units and growth in housing units are negatively related, and the change in rental rate and vacancy rate from 1980 to 1990 are positively related to the probability of FHA applications.

It can be argued that FHA loans are preferred by young households because most of them are liquidity-constrained (Duca and Rosenthal, 1994). Results support this argument. Although the individual's age is not included in the model directly, it is found that if the percentage of households with older head of household is higher in the census tract the probability of applying for an FHA loan is lower. The results show a negative relationship between average household size in the census tract and the probability of applying for an FHA loan. As expected, the probability of applying for an FHA loan is found to be higher in central cities than in suburbs, controlling for individual characteristics and economic, demographic, and housing market characteristics of census tracts.

It is very difficult to interpret these results because several variables are included in the model at the census tract level. Therefore, the results are also presented in graphical form. Two census tract characteristics are selected for the analysis because most of the recent policy changes are based on these variables. They are minority share and median family income in the census tract. Three different relative FHA application rates are shown in the graphs:

(1) Gross FHA rates,

(2) Adjusted FHA rates, controlling for individual factors,

(3) Adjusted FHA rates, controlling for individual and neighborhood factors. ${ }^{16}$

${ }^{16}$ The gross FHA rates are the observed FHA rates as shown in Table II. The adjusted FHA rates are calculated by deducting the estimated FHA rates from the gross FHA rates. They are normalized to have the same mean as the gross FHA rates. The adjusted FHA rates, controlling for individual factors, correspond to the residuals from the linear probability model. The individual and neighborhood adjusted FHA rates are calculated by including all variables except the variable against which the graph is drawn. For example, minority shares, their splines, and the change in minority share between 1980 and 1990 are not included in exploring the effect of minority percentage in the neighborhood. These residuals can be interpreted as deviations from the predicted FHA activity in a census tract with all white and with zero or negative change in minority share from 1980 to 1990. Similarly, median family income, its splines, and the dummy variables for the changes in median family income are not included in investigating the effects of median family income. The estimated residuals can be interpreted as deviations of the FHA application rate from a hypothetical neighborhood with an average tract income. Census tracts are ranked on the basis of the variable under investigation and are weighted based on the total loan applications. In order to make the comparisons easier, the probability of applying for an FHA loan is assumed to be zero in tracts with 0 or $1 \%$ minority share, or tracts with an $\$ 80,000$ or higher median family income. Each point in the graphs represents the weighted average of FHA activity in the corresponding census tracts. For example, if there are 100 tracts with $100 \%$ minority population, the weighted mean of the FHA activity of these tracts is taken in order to get a corresponding figure for all-minority census tracts. 


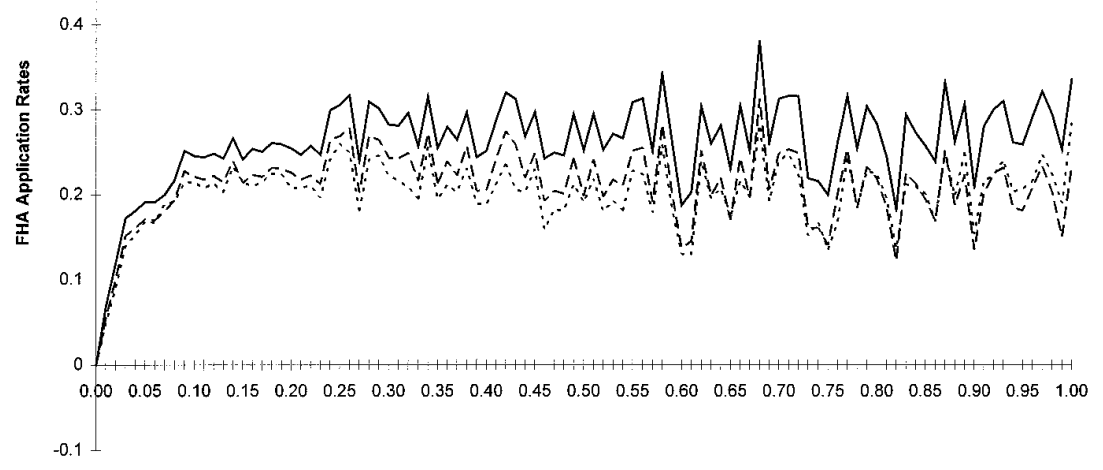

Minority Share in Census Tract

FIG. 1. FHA application rates versus minority share in census tract (Model II).

The next two subsections examine the effect of two neighborhood characteristics on relative FHA application rates.

The Effect of Racial Composition in Census Tract. Figure 1 shows that other than the initial increase from an all-white to a 10-percent minority share, the relative FHA application rates fluctuate randomly over different minority shares in the census tract. ${ }^{17}$ The data indicate that minority share affects FHA applications when the shift is from an all-white to any mixed census tract within the same MSA (Model II). However, it does not show any systematic effect on FHA application rates in any mixed or minority census tracts. Although individual factors explain some of the variation in moderately and highly minority populated census tracts, other neighborhood factors do not explain much of the variation in neighborhoods. The sharp increase from an all-white to a $10 \%$ minority census tract may be explained by the low supply of FHA loans. Unavailability of FHA loans may lead to a very small FHA applications rate in these census tracts.

17 The figure does not change much when all neighborhoods are compared without controlling for the MSA (Model I). Except the initial increase in the FHA application rate from all white to any minority neighborhoods, the fluctuations on the relative FHA application rates are observed in all neighborhoods. The difference is observed only in highly minority-populated census tracts. Even though individual factors explain some of the variation in the more than 90\% minority-populated neighborhoods, when other neighborhood factors are controlled in addition to the individual factors, the relative FHA application rates are expected to be higher than the observed. 


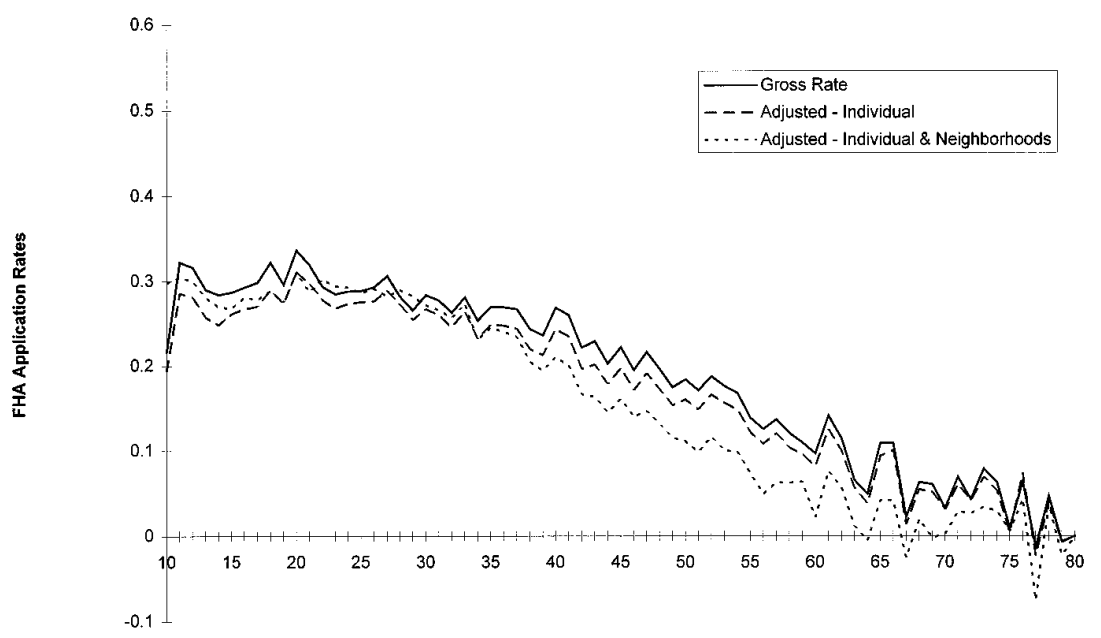

Median Family Income in Census Tract

FIG. 2. FHA application rates versus median family income in census tract (Model II).

Another explanation may be that in those census tracts, the house values are high, and because of the FHA loan limit, individuals may not be eligible for FHA loans. A similar relationship is observed when all census tracts are examined without controlling for the MSA (Model I).

Effect of Median Family Income in Census Tract. The regression results show that median family income and the probability of applying for an FHA loan are negatively correlated when the income level is above $\$ 60,000$ (Model II). Figure 2 shows a negative relationship between FHA activity and median income. According to this figure, individual factors explain very small variation in census tracts with low and moderate income levels. However, in high income census tracts, individual factors do not explain anything but census tract factors with the exception of income level related factors explaining most of the variation in FHA application rates.

When all census tracts are compared without controlling for the MSA, it is found that although the gross difference between $\$ 10,000$ and $\$ 80,000$ income census tracts is around $21.7 \%$, it increases to almost $54.8 \%$ controlling for individual and neighborhood factors (Model I). Figure 3 supports the argument that median family income in census tract is an important factor in explaining differences among census tracts. When an individual's income and race, and demographic and housing characteristics in census tract are taken into consideration, low and middle income households are expected to get more FHA loans in lower-income census tracts than the actual levels. The observed and predicted differences suggest that the FHA is expected to serve 


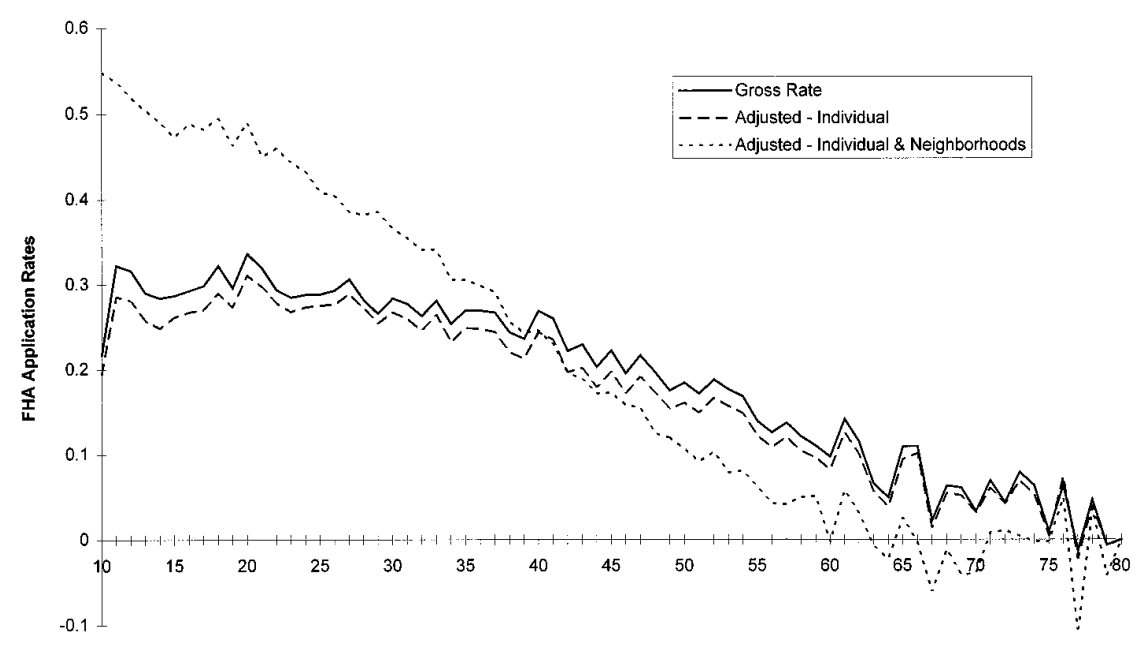

Median Family Income

FIG. 3. FHA application rates versus median family income in census tract (Model I).

more to low-income census tracts (a median income less than $\$ 30,000$ ) given an individual's income, race, and other census tract factors. Instead, in reality, it serves more than predicted in high-income census tracts.

The observed low relative FHA rate in the low-income census tracts may be because of the definition of conventional loans. In low-income census tracts, borrowers may be using a state-supported or special mortgage program available for low and middle income households. However, loans issued with these programs are treated as conventional loans in this study since the HMDA dataset does not differentiate these loans from conventional loans.

\section{FHA Originations}

The estimates for FHA originations using 1990/91 averages as dependent variables are presented in Table $\mathrm{V}$. The effects of the neighborhood characteristics on the relative FHA originations are found to be similar to their effects on applications. The signs of almost all coefficients in mortgage origination model are the same as those in the mortgage application model. The graphs also indicate that the impact of minority percentage and that of median family income in census tract on the relative FHA origination rates are similar to their impacts on the relative FHA application rates. For example, other than the initial increase in the FHA origination rates in an all-white to any mixed census tract, the relative FHA origination rates do not show any systematic relationship with respect to the minority percentage in the census tract. Similar to mortgage applications, the FHA 


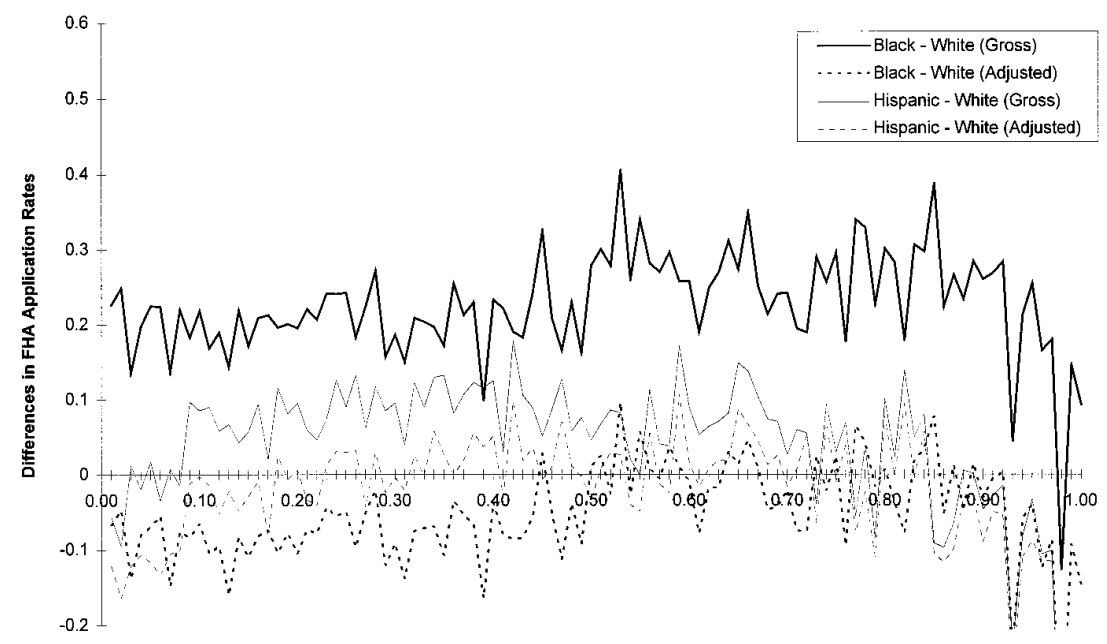

Minority Share in Census Tract

FIG. 4. Differences in gross and adjusted FHA application rates by race versus minority percentage in census tract.

origination rates are found to decrease with increases in median family income. $^{18}$

\section{Racial Differences}

The neighborhood characteristics may affect each racial group's mortgage behavior in a different way. In this section, the interaction between individual's race and the racial composition and median family income in a neighborhood are examined. ${ }^{19}$ Three racial groups are compared: whites, blacks, and Hispanics.

Minority Percentage in Census Tract. Figure 4 shows the differences in gross and adjusted FHA application rates between whites and other racial groups in census tracts with different minority shares. Although the gross relative FHA application rate for black individuals is higher than that for white individuals, when individual and neighborhood characteristics are controlled, it is found that blacks are expected to have lower relative FHA application rates than whites in white-populated and highly minority-

${ }^{18}$ The graphs are similar to graphs of mortgage applications. In order to continue the discussion without any interruption from graphs, they are not presented. They are available from the author upon request.

${ }^{19}$ All the remaining graphs are based on the estimations using Model II. The results with Model I are similar to the graphs presented in the paper. They are available from the author upon request. 


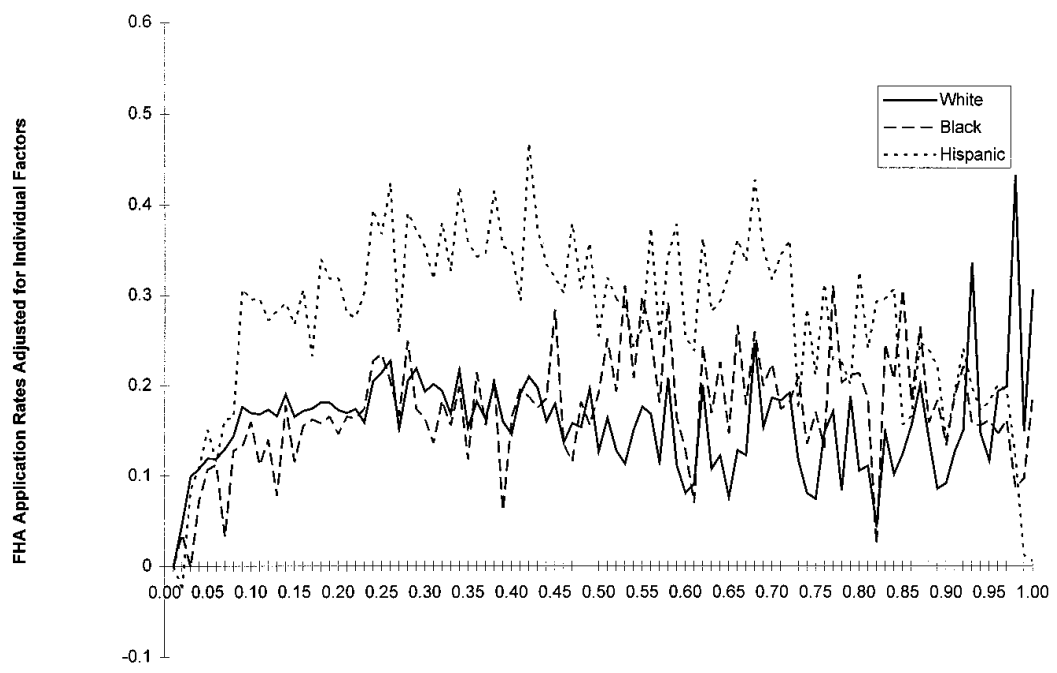

Minority Share in Census Tract

FIG. 5. FHA application rates by race controlling for individual factors versus minority percentage in census tract.

populated census tracts and the difference disappears in moderately minority-populated census tracts. The difference between Hispanics and white applicants does not decline much when individual and other neighborhood factors are controlled for.

When only individual factors are included in the model, ${ }^{20}$ white and black FHA application rates show similarities (Fig. 5). White and black mortgage applicants with the same income level have a similar probability of applying for an FHA loan in both low and moderately minority-populated census tracts. However, in very highly minority-populated census tracts, whites are expected to apply for FHA loans more often than their black counterparts. On the other hand, Hispanic borrowers with the same level of income have a higher probability of applying for an FHA loan than their white and black counterparts, controlling for their income and sex.

Median Family Income. Both the gross and adjusted differences between blacks and whites and between Hispanics and whites first increase and then fluctuate as the median income in the census tract increases (Fig. 6). However, this difference almost disappears at the higher income census tracts when individual and other neighborhood factors are controlled for.

${ }^{20}$ In this graph, the relative FHA rates, controlling for individual factors, are normalized to have a value of zero in $1 \%$ minority neighborhoods. 


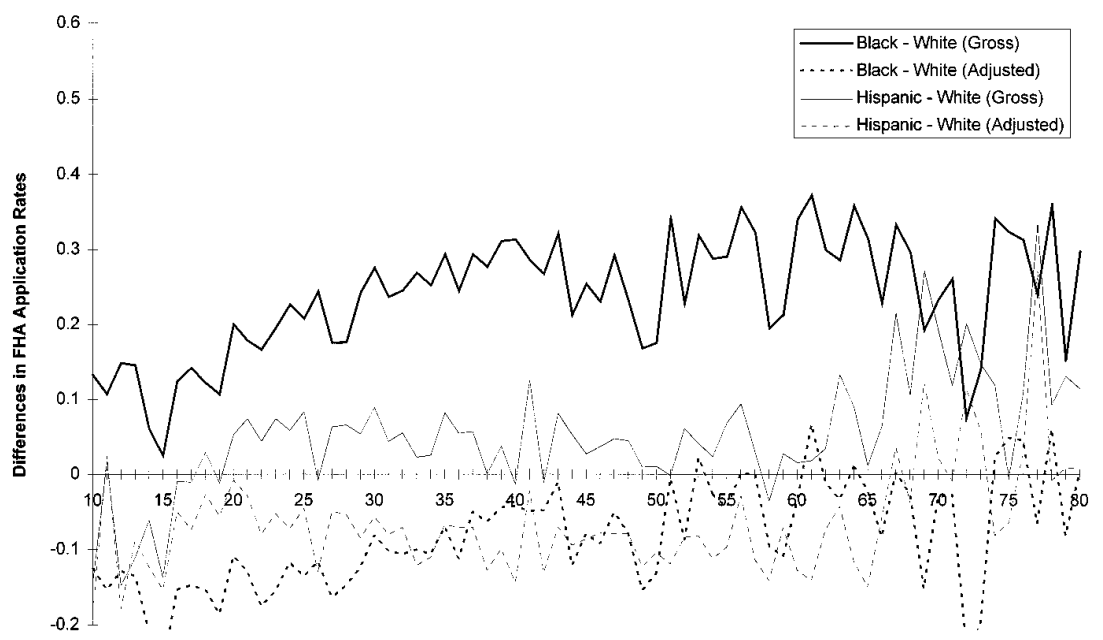

Median Family Income

FIG. 6. Differences in gross and adjusted FHA application rates by race versus median family income in census tract.

Hence, the difference between racial groups in FHA application rates can be explained by income and sex of applicant and neighborhood characteristics. Interestingly, in the low income census tracts, controlling for individual and neighborhood factors, whites are expected to have higher relative FHA application rates than their black counterparts. This is also observed when Hispanic applicants are compared with white applicants. When only individual factors are controlled for, whites' relative FHA application rates decline with the median family income (Fig. 7), but blacks' and Hispanics' relative FHA application rates show a quadratic relationship with median family income.

Although the gross and adjusted differences are found to be showing similar patterns with respect to mortgage originations, the trend in FHA originations is slightly different from FHA applications when only individual factors are controlled for. For example, blacks are more likely to get FHA loans than whites in all census tracts regardless of minority share.

\section{Central Cities and Suburbs}

Central city and suburban tracts are examined separately in order to see the interaction effects of neighborhood characteristics on relative FHA rates. In central cities, FHA rates are significantly higher than in suburban census tracts, and central cities are considered to have more minority population and low income households. 


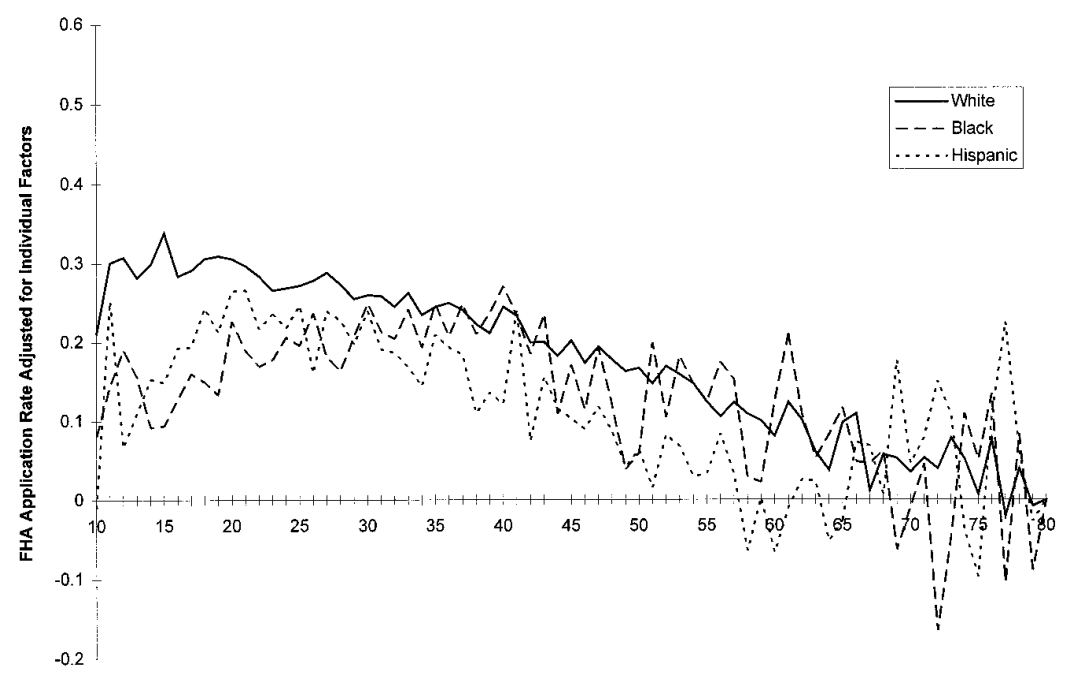

Median Family Income in Census Tract

FIG. 7. FHA application rates by race controlling for individual factors versus median family income in census tract.

When the variation in all census tracts within the same MSA is examined, it is found that the difference between central city and suburban tracts in terms of FHA application rates lowers slightly after controlling for individual and neighborhood factors in almost all census tracts regardless of the minority share (Fig. 8). Even though individual and other neighborhood factors explain some of the variation of FHA rates in central cities, they do not explain much in the suburbs. However, there is more fluctuation in relative FHA application rates in the suburbs than in central cities when minority share is more than $50 \%$. Similar to the other results, other than the initial effect, the minority percentage does not seem to affect the central city and suburban relative FHA mortgage activity systematically. These results suggest that the major difference between central cities and suburban areas can be explained by factors other than minority share in the area such as median income level. The initial difference can be explained by the unavailability of FHA loans in the almost all-white census tracts both in central cities and suburbs.

Figure 9 supports the previous argument that median income level in the area can explain the differences between central cities and suburban areas. The gap between central city and suburban tracts in terms of the gross FHA activity declines in a similar way as median income in the census tract increases. The differences between central cities and suburban areas 


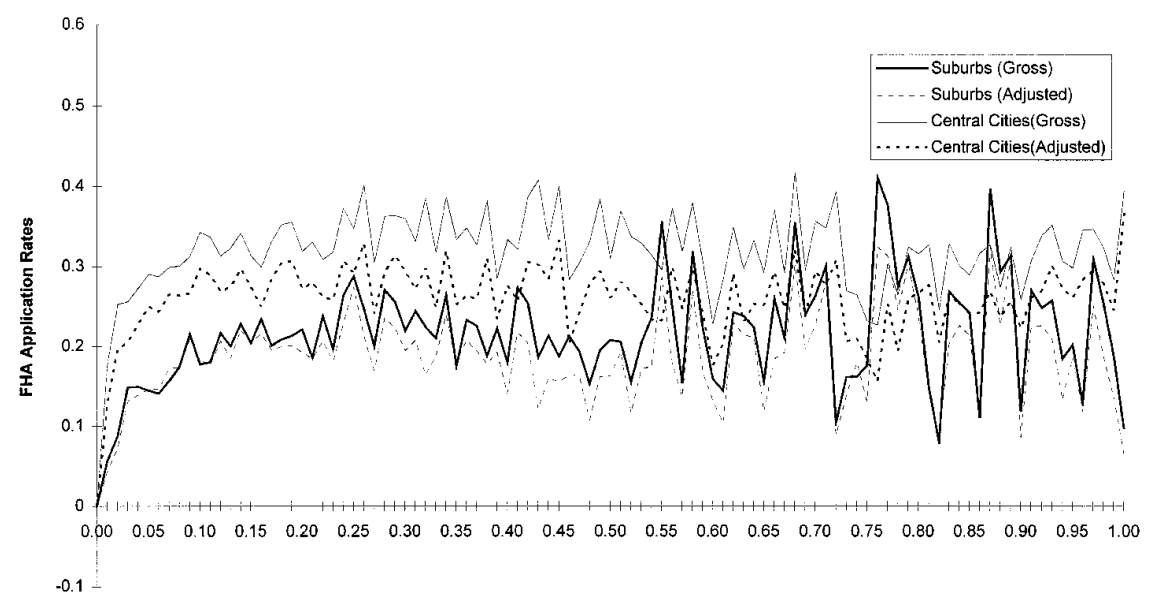

Minority Share in Gensus Tract

FIG. 8. FHA application rates by location versus minority percentage in census tract.

disappear when individual factors and other neighborhood characteristics are controlled within the same MSA. Similar to the other results, a negative relationship is observed between FHA application rates and median family income in the suburbs and central cities.

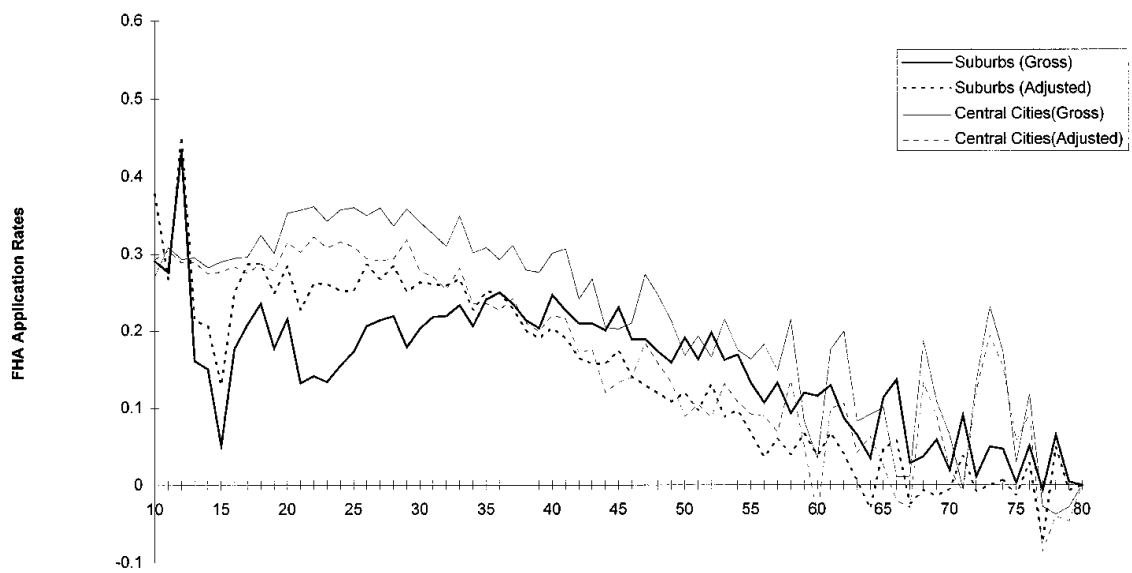

Median Family Income in Census Tract

FIG. 9. FHA application rates by location versus median family income in census tract. 


\section{CONCLUSION AND POLICY IMPLICATIONS}

This study investigates the effect of individual and neighborhood characteristics on FHA application and origination rates of low- and moderateincome households defined as those that have income less than or equal to $120 \%$ of the MSA median family income. The major findings of this study are: (1) Racial composition in a neighborhood has relatively little effect on relative FHA activity when minority share in the census tract is more than $10 \%$. (2) As median family income increases, the relative FHA activity declines. However, high relative FHA activity in low-income neighborhoods can be explained by neither individual nor neighborhood characteristics. (3) The effect of neighborhood characteristics on minority FHA applications is similar to their effect on white applications. The difference between whites and blacks in FHA activity disappears in moderate and high income and in more than 50\% minority-populated census tracts. Interestingly, whites are expected to have higher FHA activity in less than 50\% minority-populated and low income census tracts. (4) Central city and suburban FHA activity are affected in a similar way by minority percentage and median family income. The difference in FHA activity between suburban areas and central cities can be explained by the differences in median family income. (5) The individual and neighborhood characteristics affect relative FHA application and origination rates in the same way.

The evidence from the 1990 and 1991 HMDA datasets indicates that minority population in neighborhood does not have a systematic relationship with FHA activity except the movement from all-white-populated to any-minority-populated census tracts, and the FHA does play an important role in low-income census tracts which cannot be explained by individual characteristics. The finding of previous studies that blacks were more likely to get FHA loans can be explained by the higher application rate by blacks for FHA loans than by whites.

These results have several policy implications. They suggest that if the FHA's mortgage insurance programs cease, those living in low-income census tracts will be most affected. The results of this study suggest that if policies are made based on minority population among the census tract characteristics, it will not be very effective. Policies should be based on median family income in neighborhoods or census tracts.

The results should be interpreted with caution. First, several individual variables, such as wealth, credit history, debt burdens, and default risk, are not included in the model because of unavailability. They are all important in the individual's application for conventional or FHA loans. The inclusion of these factors into the model would reduce the racial difference as reported by Munnell et al. (1996) who found that even though the role of 
race diminishes with the inclusion of these variables, race was still a significant factor in the decision to grant a mortgage. The difference in the FHA application rates in the low-minority-populated and low-income census tracts might disappear when the omitted wealth and risk variables are included. Second, FHA activity is underrepresented due to the unavailability of data from small mortgage bankers. However, in general, these mortgage bankers operate in the high-minority and low-income census tracts. Since these results are obtained by excluding them, the relationship is expected to be stronger when they are included in the analysis. Low FHA activity in the very low-income census tracts might be explained by the underrepresentation of FHA activity in these census tracts because of the exclusion of small mortgage bankers' activity. Third, this study uses only the 1990 and 1991 HMDA data. Therefore, the recent changes on the FHA's mortgage insurance requirements and the effect of the Housing and Community Development Act of 1992 are not observed.

\section{APPENDIX}

TABLE A

Mean of Neighborhood Characteristics

\begin{tabular}{lcc}
\hline & \multicolumn{2}{c}{$1990-1991$ averages } \\
\cline { 2 - 3 } Neighborhood characteristics & Application & Origination \\
\hline Median house value, 1990 & $\$ 93,681$ & $\$ 94,463$ \\
Percentage change in value, 1980-1990 & 0.7224 & 0.7121 \\
Change in value dummy variables & & \\
$0.00-0.25$ & 0.1429 & 0.1458 \\
$0.25-0.50$ & 0.2875 & 0.2928 \\
$0.50-1.00$ & 0.3386 & 0.3343 \\
$1.00-1.50$ & 0.1147 & 0.1133 \\
$1.50-$ & 0.0948 & 0.0925 \\
Median family income, 1990 & $\$ 38,680$ & $\$ 39,369$ \\
Percentage change in income, 1980-1990 & 0.7618 & 0.7670 \\
Change in income dummy variables & & \\
$0.00-0.25$ & 0.0208 & 0.0184 \\
$0.25-0.50$ & 0.1279 & 0.1206 \\
$0.50-1.00$ & 0.6716 & 0.6805 \\
$1.00-1.50$ & 0.1701 & 0.1716 \\
Central city & 0.4353 & 0.4286 \\
Black share, 1990 & 0.0940 & 0.0854 \\
Change in black share, 1980-1990 & 0.0194 & 0.0183 \\
Change in black share dummy variables & & \\
$0.00-0.05$ & 0.6386 & 0.6515 \\
$0.05-0.10$ & 0.0689 & 0.0663 \\
$0.10-0.15$ & 0.0267 & 0.0247 \\
$0.15-$ & 0.0362 & 0.0327
\end{tabular}


TABLE A-Continued

1990-1991 averages

Neighborhood characteristics

Application Origination

Nonblack minority share, 1990

$\begin{array}{ll}0.1025 & 0.0975 \\ 0.0305 & 0.0294 \\ & \\ 0.6652 & 0.6802 \\ 0.0975 & 0.0947 \\ 0.0444 & 0.0417 \\ 0.0426 & 0.0393\end{array}$

Change in nonblack minority share, 1980-1990

0.0975

Change in nonblack minority share dummy variables

$0.00-0.05$
$0.05-0.10$
$0.10-0.15$
$0.15-$

Housing variables

Share of 1 unit attached

0.0603

0.0614

Share of 2 units

0.0427

0.0421

Share of 3-4 units

0.0426

0.0418

Share of 5 or more units

0.1530

0.1529

Share of mobile homes

Rental rate, 1990

0.0686

0.0643

0.2906

0.2863

Change in rental rate, 1980-1990

0.0247

0.0250

Rental rate (1-4 units), 1990

0.2112

0.2056

Change in rental rate (1-4 units)

0.0150

0.0146

Total 1-4 units, 1990

2622

2645

Growth in total housing units, 1980-1990

0.4890

0.5025

Growth in 1-4 housing units, 1980-1990

Vacancy rate, 1990

0.6901

0.7312

0.0722

0.0700

Vacancy rate, 1-4 units, 1990

Change in vacancy rate, 1980-1990

0.0585

0.0565

0.0071

0.0061

Change in vacancy rate, 1-4 units

0.0034

0.0025

Share of housing units built in 1981-1990

0.1758

0.1737

Share of housing units built in 1979-1980

0.0599

0.0609

Share of housing units built in 1975-1978

0.1391

0.1413

Share of housing units built in 1970-1974

0.1603

0.1606

Share of housing units built in 1960-1969

0.2083

0.2084

Share of housing units built in 1950-1959

0.1657

0.1656

Share of housing units built in 1940-1949

0.0906

0.0891

Share of household heads aged 25-34

0.1741

0.1753

Share of household heads aged 35-44

0.2435

0.2454

0.1812

0.1815

Share of household heads aged 45-54

0.1576

0.1567

Share of household heads aged 65-74

0.1402

0.1391

Share of household heads aged 75-

0.0879

0.0868

Average household size (owner-occupied)

2.7738

2.7712

Number of census tracts

36,641

35,464

\section{REFERENCES}

Avery, R. B., Beeson, P. E., and Sniderman, M. S. (1994). “Underserved Mortgage Markets: Evidence from HMDA Data," presented at the 1994 Western Economic Association Meetings, Vancouver, BC. 
Avery, R. B., Beeson, P. E., and Sniderman, M. S. (1993). "Leader Consistency in Housing Credit Markets," presented at the 1993 Federal Reserve Bank of Chicago Bank Structure Conference.

Barth, J. R., Cordes, J. J., and Yezer, A. M. J. (1983). "FHA Mortgage Insurance and High Risk Mortgage Lending: Some Lessons for Policy," Housing Finance Rev. 2, 93-107.

Berkovec, J., and Zorn, P. (1996). "How Complete is HMDA? HMDA Coverage of Freddie Mac Purchases,” J. Real Estate Res. 11(1), 39-55.

Bradbury, K. L., Case, K. E., and Durhan, C. R. (1989). “Geographic Patterns of Mortgage Lending in Boston, 1982-1987," New England Econ. Rev. 89, 3-30.

Brueckner, J. K. (1985). “A Simple Model of Mortgage Insurance," AREUEA J. 13(2), 129-142.

Brueckner, J. K. (1986). "Downpayment Constraint and Housing Tenure Choice: A Simplified Exposition," Reg. Sci. Urban Econ. 16(4), 519-525.

Canner, G. B. et al. (1994). "Residential Lending to Low-Income and Minority Families: Evidence from the 1992 HMDA Data," Federal Reserve Bull. 90(2), 79-108.

Canner, G. B., and Gabriel, S. A. (1992). "Market Segmentation and Lender Specialization in the Primary and Secondary Mortgage Markets," Housing Policy Debate 3(2), 241-329.

Canner, G. B., Gabriel, S. A., and Woolley, J. M. (1991). "Race, Default Risk and Mortgage Lending: A Study of the FHA and Conventional Loan Markets," Southern Econ. J. 58, 249-262.

Canner, G. B., Passmore, W., and Mittal, M. (1994). "Private Mortgage Insurance," Federal Reserve Bull. 80(10), 883-899.

Duca, J. V., and Rosenthal, S. S. (1994). "Borrowing Constraints and Access to Owneroccupied Housing," Regional Sci. Urban Econ. 24, 301-322.

Duca, J. V., and Rosenthal, S. S. (1993). "Borrowing Constraints, Household Debt and Racial Discrimination in Loan Markets," J. Finan. Intermed. 3, 77-103.

Duca, J. V., and Rosenthal, S. S. (1991). "An Empirical Test of Credit Rationing in The Mortgage Market,” J. Urban Econ. 29, 218-234.

Gabriel, S. A., and Rosenthal, S. S. (1989). "Household Location and Race: Estimates of a Multinomial Logit Model," Rev. Econ. Statist. 71, 240-249.

Gabriel, S. A., and Rosenthal, S. S. (1991). "Credit Rationing, Race and the Mortgage Market," J. Urban Econ. 29, 371-379.

Garwood, G. L., and Smith, D. S. (1993). "The Community Reinvestment Act: Evolution and Current Issues," Federal Reserve Bull. 79 (April), 251-267.

Hendershott, P. H., and Lafayette, W. C. (1994). "Sensitivity of Mortgage Choice to the Cost of FHA and PMI Default Insurance," presented at the Mid-year AREUEA meetings in Washington, DC.

Hendershott, P. H., and Thibodeau, T. G. (1990). "The Relationship Between Median and Constant Quality House Prices: Implications for Setting FHA Loan Limits," AREUEA J. 18, 323-334.

Hendershott, P. H., and Waddell, J. A. (1992). "The Changing Fortunes of FHA's Mutual Mortgage Insurance Fund and The Legislative Procedure,' J. Real Estate Finance Econ. 5, 119-132.

Kennickell, A., and Shack-Marquez, J. (1992). "Changes in Family Finances from 1983 to 1989: Evidence from the Survey of Consumer Finances," Federal Reserve Bull. 78(1), $1-18$.

Macrae, C. D., Turner, M. A., and Yezer, A. M. J. (1982). "Determinants of FHA Mortgage Insurance in Urban Neighborhoods," Housing Finance Rev. 1(1), 55-71. 
Megbolugbe, I. F., Cho, M., and Rubin, G. M. (1994). “An Empirical Analysis of Metropolitan Area Mortgage Markets: The Volume of Origination and Distribution of Conventional and FHA Mortgage Loans," presented at the mid-year AREUEA Conference, Washington, DC.

Munnell, A. H. et al. (1996). "Mortgage Lending in Boston: Interpreting HMDA Data," Amer. Econ. Rev. 86(1), 25-53.

Shear, W. B., and Yezer, A. M. J. (1983). "An Indirect Test for Differential Treatment of Borrowers in Mortgage Markets," AREUEA J. 10, 405-420.

Weicher, J. C. (1994). "The New Structure of the Housing Finance System," Federal Reserve Bank of St. Louis Rev. 76(4), 47-65.

Yinger, J. (1991). Housing Discrimination Study: Incentive and Severity of Unfavorable Treatment, The Urban Institute, Washington, D.C. 